\title{
PENDAMPINGAN DAN PENERAPAN MODUL HEALING TOUCH DALAM MENGATASI KECEMASAN PADA PERSALINAN OLEH BPM KOTA PEKANBARU
}

\author{
${ }^{1)}$ Yan Sartika, ${ }^{2)}$ Elly Susilawati, \\ 1,2,)Program Studi D4 Kebidanan, Poltekkes Kmenkes Riau \\ 1,2,) Jl. Riau Melur No 103 Kec Sukajadi Kota Pekanbaru Riau, Indonesia \\ E-mail : Yansartika1980@gmail.com,Ellysusilawatiramli@gmail.com
}

\begin{abstract}
ABSTRAK
Tujuan dilakukannya kegiatan pengabdian kepada masyarakat ini adalah melakukan sosialisasi tentang metode Healing Touch bagi bidan dan menggerakkan bidan untuk menerapkan metode Healing Touch sebagai alat bantu melakukan skrining dalam upaya deteksi dini masalah psikologis pada ibu hamil di Bidan Praktik Mandiri Kota Pekanbaru Tahun 2019. Metode kegiatan pengabdian masyarakat ini dilakukan dengan cara melakukan sosialisasi metode Healing Touch kepada bidan dilanjutkan dengan monitoring dan evaluasi terhadap penerapan metode Healing Touch oleh bidan. Hasil kegiatan pengabdian kepada masyarakat ini adalah telah dilaksanakan kegiatan sosialisasi metode Healing Touch kepada bidan di BPM Dince Safrina, BPM Siti Julaeha dan Klinik Pratama Afiyah, dilanjutkan dengan praktik penerapan metode Healing Touch pada ibu hamil di tiga BPM/Klinik tersebut. Berdasarkan hasil monitoring dan evaluasi didapatkan peningkatan pengetahuan peserta dengan nilai rata-rata dari 54,6 menjadi 79,3, dan pada penerapan metode Healing Touch oleh bidan untuk deteksi dini masalah psikologis ibu hamil didapatkan nilai rata-rata yaitu 70,6. Disarankan kepada bidan dapat meningkatkan lagi upaya deteksi dini kecemasan dalm kehamilan sampai menjelang persalinan pada setiap ibu hamil dengan menggunakan metode Healing Touch baik pada saat kunjungan rumah maupun saat klien berkunjung ke fasilitasi pelayanan.
\end{abstract}

Kata Kunci : Healing Touch, Kecemasaan kehamilan, kecemasan persalinan

\begin{abstract}
The purpose of this community service activities is to conduct socialization about the Healing Touch method for midwives and mobilizing them to apply the Healing Touch method as a tool for screening early efforts to detect psychological problems for expectant mother in Independent Midwifery Practice of Pekanbaru in 2019. The method of community service activities is carried out by conducting socialization about the Healing Touch method for midwives followed by monitoring and evaluating the application of Healing Touch method by midwives. The results of this activities are the socialization of Healing Touch method for midwives at BPM Dince Safrina, BPM Siti Julaeha and Pratama Afiyah Clinic, followed by the practice of applying the Healing Touch method to expectant mother at the three BPM/Clinic.Based on the results of monitoring and evaluation obtained an enhancement in participants' knowledge with an average value from 54.6 to 79.3, and the application of the Healing Touch method by midwives for early detection of psychological problems in pregnant women obtained an average value of 70.6. It is recommended for midwives to improve their efforts to detect anxiety in pre-term pregnancy until birth delivery to every expectant mother by using the Healing Touch method both during home visits and when the clients visit service facility.
\end{abstract}

Keywords : Healing Touch, Pregnancy anxiety, Delivery Anxiety

\section{PENDAHULUAN}

Kecemasan pada ibu hamil apabila tidak ditangani dengan serius akan membawa dampak dan pengaruh terhadap fisik dan psikis, baik pada ibu maupun janin. Ibu yang mengalami kecemasan atau stres, sinyalnya berjalan lewat aksis HPA (Hipotalamo-Pituitary-Adrenal) yang dapat menyebabkan lepasnya hormon stres antara lain Adreno Cortico Tropin Hormone (ACTH), kortisol, katekolamin, ß-Endorphin, Growth Hormone $(\mathrm{GH})$, prolaktin dan Lutenizing Hormone (LH) / Folicle Stimulating Hormone (FSH). Lepasnya hormon-hormon stres tersebut mengakibatkan terjadinya vasokonstriksi sistemik, termasuk di antaranya konstriksi vasa utero plasenta yang menyebabkan gangguan aliran darah ke dalam rahim yang menyebabkan terjadi gangguan pada janin sehingga memperpanjang persalinan kala 1 atau terjadinya partus lama. 
Partus lama rata-rata di dunia menyebabkan kematian ibu sebesar $8 \%$. Di samping itu dengan meningkatnya plasma kortisol, berakibat menurunkan respon imun ibu dan janin [1]

Healing touch merupakan cara mengurangi rasa cemas dimana dengan cara sentuhan. Healing touch tersebut diperkenalkan pada awal tahun 1970 oleh Delores Krieger dan Dora Kuntz sebagai intervensi keperawatan noninvasif yang berasal dari penyembuhan dunia timur kuno [2][3]

Beberapa penelitian menemukan adanya pengaruh healing touch terhadap penyakit kanker dengan didapatkannya hasil positif atau lebih baik bagi pasien kanker. Hal ini menunjukkan adanya kebutuhan untuk mengeksplorasi terapi non tradisional modalitas. Healing touch sebagai pilihan yang layak untuk melengkapi terapi kanker standar. Healing touchdalam penelitian ini menggambarkan bahwa dengan sentuhan dapat mengurangi nyeri dan kecemasan akibat penyakit kanker yang diderita pasien [4][5]. Melakukan sentuhan yang amat ringan pada tubuh. Healing touchquantum dipilih oleh peneliti dikarenkan merupakan terapi yang tidak memiliki efek samping dan lebih efisien, dengan hanya cukup memusatkan energi pada tangan kemudian melakukan sentuhan yang akan mentaransfer energi terapis yang berenergi positif sehingga pasien yang diberikan terapi akan membaik karena terpengaruh oleh energi dari terapis tersebut [6][7] .

Dalam penelitian tersebut telah dihasilkan modul Senam hamil dan Healing touch yang terbukti dapat menurunkan kadar kortisol dan kecemasan dalam menghadapi persalinan. Mengingat pentingnya manajemen kecemasan menghadapi persalinan pada ibu bersalin normal, maka dipandang perlu diterapkan oleh semua bidan yang memberikan pelayanan pertolongan persalinan normal, khususnya di Bidan Praktik Mandiri (BPM). Berdasarkan data IBI Cabang Kota Pekanbaru, terdapat sebanyak 228 Bidan Praktik Mandiri (BPM). Dalam pengabdian kepada masyarakat tahun 2019 ini akan dilakukan terhadap 3 bidan praktik mandiri yaitu BPM Siti Julaeha, BPM Dince Safrina dan Klinik Pratama Afiyah Kota Pekanbaru

\section{METODE PELAKSANAAN}

Kegiatan pengabdian masyarakat ini dilaksanakan pada bulan April sampai Juli 2019. Lokasi dilaksanakan di 3 Tempat yang berbeda yaitu BPM Siti Julaeha (Panam), BPM Dince Safrina (Rumbai) dan Klinik Pratama Afiyah (Muara Fajar) Kota Pekanbaru

1. Melakukan sosialisasi Healing Touch kepada bidan dilakukan sebanyak tiga kali dengan riancian : tanggal 19 Juni 2019 di BPM Dince Safrina, tanggal 20 Juni 2019 di Klinik Pratama Afiyah, tanggal 21 Juni 2019 di BPM Siti Julaeha Kota Pekanbaru

2. Melakukan Pendampingan dan penerapan Healing Touch pada pasien post partum dilakukan sebanyak tiga kali dengan rincian : di BPM Dince Safrina pada tanggal 5 Juli 2019, di BPM Siti Julaeha pada tanggal 8 Juli 2019, di Klinik Pratama Afiyah pada tanggal 9 Juli 2019.

3. Melakukan monitoring dan Evaluasi penerapan Healing Touch oleh bidan yaitu pada tanggal 17 Juli di BPM Dince Safrina, tanggal 18 Juli 2019 di BPM Siti Julaeha, dan pada tanggal 19 Juli di Klinik Pratama Afiyah Kota Pekanbaru.

\section{Kerangka Kerja Pengabdian}

Untuk mempermudah dalam kegiatan pengabdian ini, maka penulis membuatkan kerangka kerja kegiatan seperti pada gambar berikut ini. 


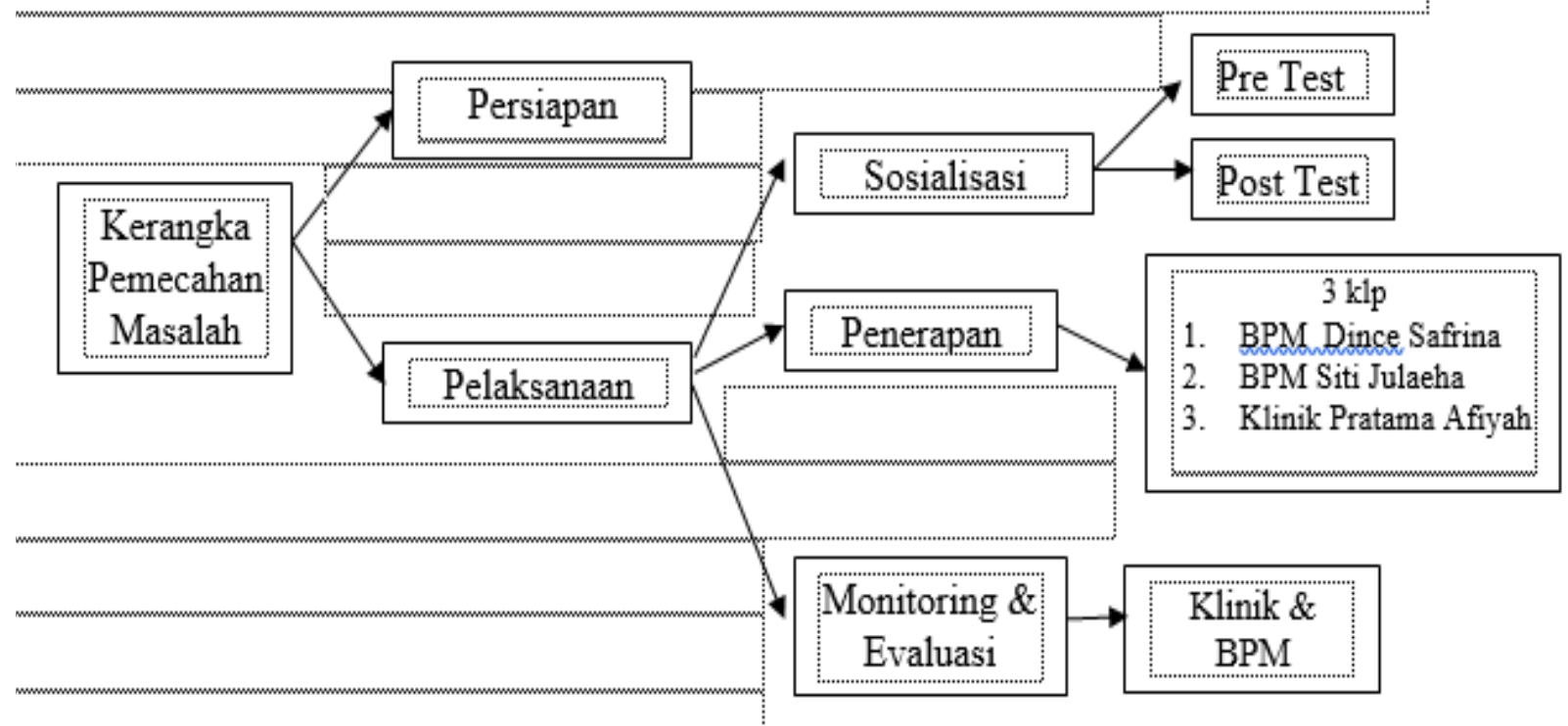

Gambar 1. Kerangka Kerja Kegiatan Pengabdian

\section{HASIL}

Pelaksanaan kegiatan pengabdian kepada masyarakat tentang Sosialisasi dan penerapan model Healing Touch oleh Bidan di BIdan Praktek Mandiri Kota Pekanbaru telah dilaksanakan melalui beberapa tahapan yaitu dilakukannya sosialisasi Healing Touch kepada bidan pada tanggal 19 Juni 2019 di BPM Dince Safrina, 20 Juni 2019 di Klinik Pratama Afiyah dan pada 21 Juni 2019 bertempat BPM Siti Julaeha. Kegiatan dilanjutkan dengan melakukan praktik penerapan Healing Touch pada ibu hamil yang ada di masing-masing BPM/Klinik tersebut dengan membagi tiga kelompok, di BPM Dince Safrina pada tanggal 5 Juli 2019 (6 orang bidan), di BPM Siti Julaeha pada tanggal 8 Juli 2019 (3 orang bidan) dan di Klinik Pratama Afiyah pada tanggal 9 Juli 2019 (6 orang bidan). Monitoring dan Evaluasi penerapan Healing Touch oleh bidan dilakukan pada tanggal 17 Juli 2019 di BPM Dince Safrina, Pada tanggal 18 Juli 2019 di BPM Siti Julaeha dan pada tanggal 19 Juli 2019 di Klinik Pratama Afiyah. Hasil kegiatan sosialisasi dan penerapan Healing Touch dapat dilihat pada tabel-tabel berikut.

\section{Tabel 1.}

Gambaran Pengetahuan Bidan tentang metode Healing Touch Sebelum dan Sesudah Sosialisai Di Bidan Praktik Mandiri Kota Pekanbaru

\begin{tabular}{ccccc}
\hline No & & Pengetahuan & $\mathrm{n}$ & $\%$ \\
\hline 1 & Pre Test & 15 & 54,6 \\
\hline 2 & Post Test & 15 & 79,3 \\
\hline
\end{tabular}

Pada tabel 1 dapat dilihat bahwa Pengetahuan bidan tentang metode Healing Touch secara umum sebelum dilakukan sosialisasi sebesar 54,6 \% dan setelah dilakukan Sosisalisasi sebesar $79,3 \%$. 
Tabel 2.

Perbandingan rata-rata nilai Pengetahuan Bidan tentang metode Healing Touch berdasarkan Hasil Pretest dan Post test

\begin{tabular}{cllcc}
\hline No & Sampel & BPM/KLinik & Pre Test & Post Test \\
\hline 1 & S & BPM Siti Julaeha & 60 & 90 \\
\hline 2 & W & BPM Siti Julaeha & 40 & 70 \\
\hline 3 & M & BPM Siti Julaeha & 50 & 50 \\
\hline 4 & D & BPM Dince Safrina & 70 & 90 \\
\hline 5 & J & BPM Dince Safrina & 50 & 80 \\
\hline 6 & R & BPM Dince Safrina & 60 & 90 \\
\hline 7 & N & BPM Dince Safrina & 50 & 70 \\
\hline 8 & F & BPM Dince Safrina & 80 & 100 \\
\hline 9 & S & BPM Dince Safrina & 30 & 60 \\
\hline 10 & F & Klinik Pratama Afiyah & 80 & 90 \\
\hline 11 & R & Klinik Pratama Afiyah & 60 & 90 \\
\hline 12 & S & Klinik Pratama Afiyah & 50 & 70 \\
\hline 13 & T & Klinik Pratama Afiyah & 40 & 70 \\
\hline 14 & H & Klinik Pratama Afiyah & 40 & 80 \\
\hline 15 & V & Klinik Pratama Afiyah & 60 & 90 \\
\hline & Total & & 820 & 79,3 \\
\hline & Rata-rata & & 54,6 & 190 \\
\hline
\end{tabular}

Pada tabel 2 dapat dilihat bahwa rata-rata nilai pengetahuan bidan tentang metode Healing Touch sebelum dan sesudah dilakukan sosialisasi tentang metode Healing Touch mengalami peningkatan yaitu dari rata-rata nilai 54,6 menjadi rata-rata 79,3.

Tabel 3.

Gambaran Kemampuan Penerapan Bidan tentang metode Healing Touch Setelah Sosialisasi Di Bidan Praktik Mandiri Kota Pekanbaru

\begin{tabular}{|c|c|c|c|}
\hline No & Sampel & BPM/KLinik & $\begin{array}{l}\text { Nilai Yang } \\
\text { Didapat }\end{array}$ \\
\hline 1 & $\mathrm{~S}$ & BPM Siti Julaeha & 70 \\
\hline 2 & $\mathrm{~W}$ & BPM Siti Julaeha & 60 \\
\hline 3 & $\mathrm{M}$ & BPM Siti Julaeha & 70 \\
\hline 4 & $\mathrm{D}$ & BPM Dince Safrina & 70 \\
\hline 5 & $\mathrm{~J}$ & BPM Dince Safrina & 80 \\
\hline 6 & $\mathrm{R}$ & BPM Dince Safrina & 60 \\
\hline 7 & $\mathrm{~N}$ & BPM Dince Safrina & 60 \\
\hline 8 & $\mathrm{~F}$ & BPM Dince Safrina & 90 \\
\hline 9 & $\mathrm{~S}$ & BPM Dince Safrina & 70 \\
\hline 10 & $\mathrm{~F}$ & Klinik Pratama Afiyah & 80 \\
\hline 11 & $\mathrm{R}$ & Klinik Pratama Afiyah & 70 \\
\hline 12 & $\mathrm{~S}$ & Klinik Pratama Afiyah & 60 \\
\hline 13 & $\mathrm{~T}$ & Klinik Pratama Afiyah & 70 \\
\hline
\end{tabular}




\begin{tabular}{clcc}
\hline 14 & $\mathrm{H}$ & Klinik Pratama Afiyah & 70 \\
\hline 15 & $\mathrm{~V}$ & Klinik Pratama Afiyah & 80 \\
\hline & Total & 1060 \\
\hline & & 70,6
\end{tabular}

Pada tabel 3 dapat dilihat bahwa rata - rata kemampuan bidan dalam penerapan Healing Touch pada ibu hamil sebesar 70,6.

\section{Dokumentasi Kegiatan}

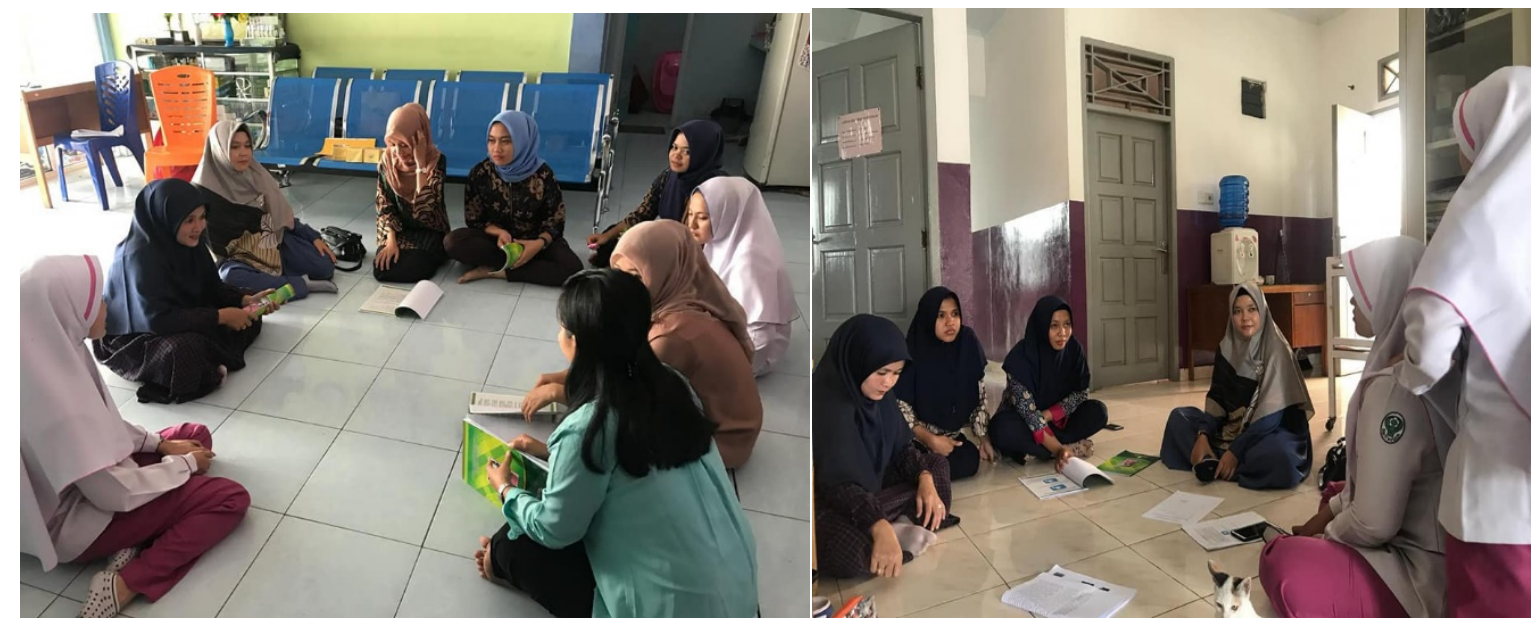

Gambar 1 : Sosialisasi Healing Touch kepada bidan
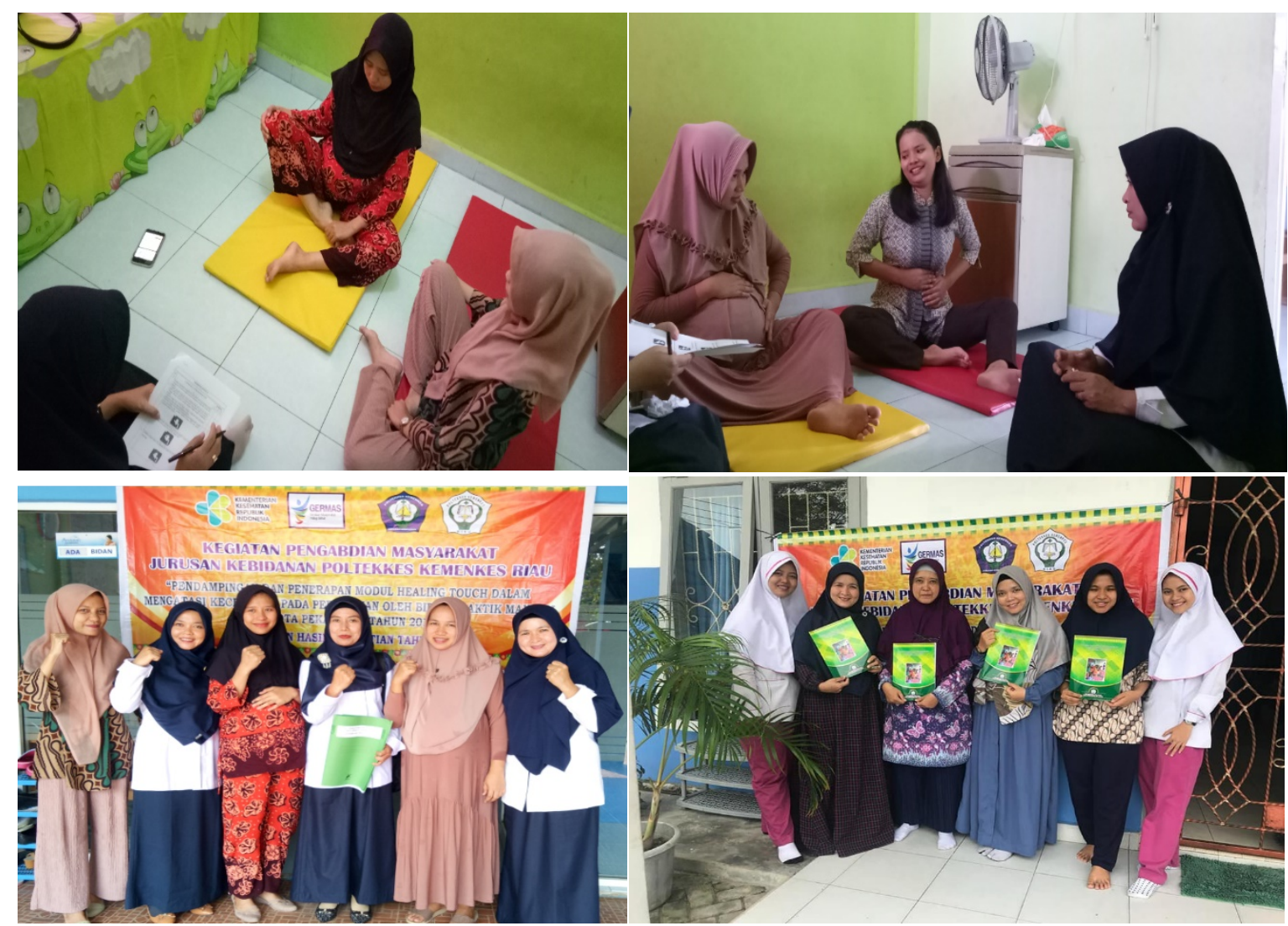

Gambar 2 : pendampingan, penerapan dan evaluasi pelaksanaan modul Healing Touch 


\section{KESIMPULAN}

Dari kegiatan Pengabdian kepada masyarakat tentang sosialisasi dan penerapan metode Healing Touch oleh bidan di Bidan Praktik Mandiri Kota Pekanbaru dapat disimpulkan

a. Hasil pretest dan posttest menunjukkan bahwa terdapat peningkatan pengetahuan peserta, yaitu dari rata-rata nilai 54,6 menjadi rata-rata 79,3.

b. Rata - rata Nilai Penerapan metode Healing Touch oleh bidan untuk deteksi dini masalah psikologis ibu hamil adalah sebesar 70,6.

\section{DAFTAR PUSTAKA}

[1] E. Jackson, M. Kelley, P. McNeil, E. Meyer, L. Schlegel, and M. Eaton, "Does therapeutic touch help reduce pain and anxiety in patients with cancer?," Clin. J. Oncol. Nurs., vol. 12, no. 1, pp. 113-120, 2008.

[2] R. Gordon, Quantum-Touch: The power to heal. North Atlantic Books, 2011.

[3] L. S. B. A. \& Wolfman, “済無No Title No Title,” J. Chem. Inf. Model., vol. 53, no. 9, pp. 1689-1699, 2013.

[4] H. G. Kim, M. Mandell, C. Crandall, M. A. Kuskowski, B. Dieperink, and R. L. Buchberger, "Antenatal psychiatric illness and adequacy of prenatal care in an ethnically diverse innercity obstetric population," Arch. Womens. Ment. Health, vol. 9, no. 2, pp. 103-107, 2006.

[5] S. Niaz, N. Izhar, and M. R. Bhatti, "Anxiety and depression in pregnant women presenting in the OPD of a teaching hospital," Pakistan J. Med. Sci., vol. 20, no. 2, pp. 117-119, 2004.

[6] I. Puty and A. Wibowo, "Pengaruh Keikutsertaan Senam Hamil Terhadap Kecemasan Primigravida Trimester Ketiga Dalam Menghadapi Persalinan," J. Biometrika dan Kependud., vol. 1, pp. 26-32, 2012.

[7] H. E. Nasreen, Z. N. Kabir, Y. Forsell, and M. Edhborg, "Prevalence and associated factors of depressive and anxiety symptoms during pregnancy: A population based study in rural Bangladesh," BMC Womens. Health, vol. 11, 2011. 